\title{
Sarcosine Measurement
}

National Cancer Institute

\section{Source}

National Cancer Institute. Sarcosine Measurement. NCI Thesaurus. Code C154760.

The determination of the amount of sarcosine present in a sample. 